\title{
AN ANALYSIS OF BEHAVIOURAL CHARACTERISTICS IN CHILDREN WITH UNINTENTIONAL POISONING
}

\author{
${ }_{1}^{1}$ Associate Professor, Department of Paediatrics, Government Medical College, Kottayam. \\ ${ }^{2}$ Assistant Professor, Department of Paediatrics, Government Medical College, Kottayam. \\ ${ }_{3}^{3}$ Associate Professor, Department of Paediatrics, Government Medical College, Kottayam. \\ ${ }^{4}$ Additional Professor, Department of Paediatrics, Government Medical College, Kottayam. \\ ${ }^{5}$ Director, IUCDS, School of Behavioural Sciences, Mahatma Gandhi University, Kottayam.
}

Jiji Mary Antony1, Bindhu Krishnan Padma², Suresh S. Vadakedom³, Darly Saramma Mammen ${ }^{4}$, Baburaj Palamkunnil Thankappan ${ }^{5}$

\begin{abstract}
\section{BACKGROUND}

Unintentional poisoning is the major cause of morbidity in children. ${ }^{1}$ More than $50 \%$ of the poisoning occurs in children under the age of 6. Younger children with their natural curiosity and with their recently acquired hand skills and mobility explore more and may accidentally get poisoned. These age group children are undergoing the oral stage of their psychological development. Hence, most childhood poisoning occurs from ingestion. ${ }^{2}$
\end{abstract}

\section{MATERIALS AND METHODS}

This is a case control analytical study. Purposive sampling method was used for the study. The population in this study were children below 5 years of age who were admitted with unintentional poisoning in Government Medical College, Kottayam during the study period. Studied 23 cases and 23 controls. The tools used for the study were clinical examination proforma, CBCL $1 \frac{1 / 2-5}{1}$ years questionnaire. Mann-Whitney U test was used for analysis of data. The study focused to determine, which problem items tend to occur together for a syndrome in a child with unintentional poisoning.

\section{RESULTS}

The total score of CBCL were found to be high in children with unintentional poisoning (median of 58) compared to the children without poisoning (median of 48). Children with unintentional poisoning were having CBCL 11/2- 5 scores with a median value closer to maximum scores in the aspects of withdrawn $(2,4)$; attention problems $(5,9)$; aggressive behaviour $(13,23)$; internalising $(12,23)$; externalising $(18,28)$ and total problems $(45,80)$. Compared to the control group, children with unintentional poisoning were having significant increase in internalising problems like withdrawn nature and somatic complaints and externalising problems like aggression and attention problems. Sleep problems were also found to be increased in children with unintentional poisoning compared to age and sex matched controls.

\section{CONCLUSION}

Internalising and externalising problems were found to be increased in children with unintentional poisoning. So the parents can be made aware of the behaviours of the child which can lead to poisoning and precautionary methods can be taken.

\section{KEYWORDS}

Poison, Problem Behaviour, Exploratory Behaviour, Oral Stage.

HOW TO CITE THIS ARTICLE: Antony JM, Padma BK, Vadakedom SS, et al. An analysis of behavioural characteristics in children with unintentional poisoning. J. Evolution Med. Dent. Sci. 2017;6(92):6607-6612, DOI: 10.14260/jemds/2017/1432

\section{BACKGROUND}

Unintentional poisoning is the major cause of morbidity in children. ${ }^{1}$ More than $50 \%$ of the poisoning occurs in children under the age of 6 . Younger children with their natural curiosity and with their recently acquired hand skills and mobility explore more and may accidentally get poisoned. These age group children are undergoing the oral stage of their psychological development. Hence, most childhood poisoning occurs from ingestion. ${ }^{2}$ According to WHO, acute poisoning accounts for an estimated 45,000 deaths annually among children and youth under the age of 20 years. It is highest among infants and decrease with age until 14 years.

'Financial or Other Competing Interest': None.

Submission 04-08-2017, Peer Review 15-11-2017,

Acceptance 21-11-2017, Published 04-12-2017.

Corresponding Author:

Dr. Jiji Mary Antony,

Eden, Vathalloor.

Thellakom P. O., Kottayam, Kerala.

E-mail: jijimaryantony@yahoo.com

DOI: $10.14260 /$ jemds $/ 2017 / 1432$

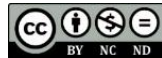

In India, the fatality rate ranged from $0.6 \%$ to $11.6 \%{ }^{3}$ Childhood poisoning result from a complex interaction between the child, the agent and the environment. Personality characteristics may influence injury risk. In a retrospective study done by Dr. J R Sibert, children who had poisoning were significantly more anxious, harder and more active than controls. 4 In some studies, it was found that children with a previous episode of poisoning were at increased risk for subsequent poisoning event.

Children with a tendency for hyperactiveness, destructiveness and uncooperativeness were more likely to take poisons. ${ }^{5}$ Both internalising and externalising disorders were higher in children with unintentional injury in a study conducted in children by Ethem Acar. ${ }^{6}$ Attention deficit hyperactivity disorder, characterised by overactivity, inattention and impulsivity in the child is one of the most common childhood disorders associated with unintentional injury to the child.7-8

The present study was intended to see which were the behavioural characteristics that make these children more prone to accidental poisoning. If the behavioural characteri- 
stics are known, then precautionary methods can be taken to prevent injury and poisoning.

According to the WHO and the United Nations Children's Fund (UNICEF), poisoning in childhood is common because children are curious and explore their world with all their senses including taste.

In childhood mental health problems are mainly of two types- Internalising problems (emotionally reactive, anxious, somatic complaints and withdrawn) and externalising problems (attention problems and aggressive behaviour). These problems affect one-fourth of the population.

In a longitudinal study by Bayer (2012), a population based Australian sample found that the children with persistent mental health symptoms can be identified in the early toddler years. ${ }^{9}$ A detailed understanding through the early childhood years of internalising and externalising trajectories compared to the available norms could inform prevention initiatives for mental health.

From childhood to adolescence to adulthood, the externalising behaviour increases the injury risk. A study by Jokela et al (2009) showed that the childhood problem behaviours can predict injury risk over the life course. ${ }^{10}$

In the study by Basavaraj (1982), it was seen that mothers of the children with poisoning noticed that the children were noisy, aggressive and rough. ${ }^{11} \mathrm{~A}$ study by De la Osa N (2016) to find out the discriminative capacity of CBCL 1 1/2-5-DSM5 scaled to identify the disruptive and internalising disorders in preschool children. The findings were- CBCL 1 1/2-5 -DSM5 scales achieved good discriminative capacity for ADHD. Parents will know how a child behaves in his own environment, which is the relevant factor in childhood poisoning. The interaction between the child's personality and the family situation are important aetiologically. 12

With the CBCL 11/2- 5 yrs./ DSM V scores we can find out the normal range, borderline clinical and clinical ranges of problems in children. Scores in the borderline and clinical ranges significantly discriminate between children who need professional help for mental health services. From previous works by researchers shows that there is a strong relationship between behavioural problems and accidental poisoning.(13-14) In this context, the investigator intended to conduct this study.

\section{Objectives of the Study-}

1. To identify the behaviour problems in children with unintentional poisoning.

2. To compare the behaviour problems in children with unintentional poisoning and in those children who were not poisoned.

\section{MATERIALS AND METHODS}

This is a case control analytical study. Case is an individual with disease or outcome of interest. In this study, case is defined as children with unintentional poisoning between age group 1.5 to 5 years satisfying the inclusion criteria. Control is an individual who does not have the disease or outcome of interest. In the present study control is defined as children without unintentional poisoning, but who came to the hospital and was admitted for minor illnesses who were matched for age and sex with the children with unintentional poisoning. Exposure in this study is the behavioural problems. The investigator tried to find out whether the exposure, that is the behavioural problem was present in children who were admitted with unintentional poisoning and to see whether the exposure is absent in controls.

Purposive sampling method was used for the study. Ethical clearance was obtained from the Ethics Committee of Govt. Medical College, Kottayam, Kerala. The population in this study were children below 5 years of age who were admitted with unintentional poisoning during the study period of October 2016 to September 2017. During this period of study, 23 cases were admitted in the hospital satisfying the inclusion criteria. So the sample comprised of 23 cases. Written informed consent was taken from the parent before the study. Cases were selected as children between 1.5 years and 5 years who were admitted with unintentional minor poisoning and satisfying the inclusion criteria. The controls were taken from the hospital, matched for age and sex as and when the cases were admitted and studied.

The tools used for the study were clinical examination proforma, CBCL 11/2- 5 years questionnaire for the parent of children with age 1.5 to 5 years.

\section{Sample Size}

According to a study conducted by Ethem Acar et al on unintentional injuries in preschool age children at Turkey, DOI 10.1097/MD.0000000000001378, CBCL internalising score in study group was found to be $17.5 \pm 9.1$ and that of control group was $10.4 \pm 7.9$

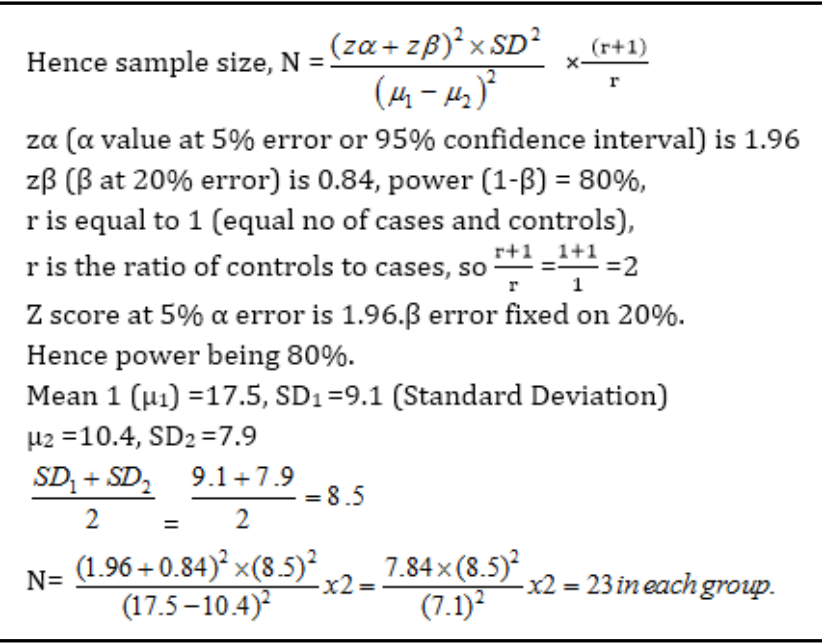

So, the investigator took 23 cases and 23 controls as sample size for the study.

\section{Child Behaviour Checklist}

The Child Behaviour Checklist (CBCL 11/2- 5) measures behavioural, social and emotional problems in children of age $11 / 2-5$. The tool consists of 100 items in 7 syndrome scales. The syndrome scale consists of 4 internalising domains and 2 externalising domains and sleep problem domain. The internalising score is a combination of emotionally reactive, anxious, depressed, somatic complaints and withdrawn scores and externalising problem score formed by combining attention problems and aggressive behaviour score. The parents were informed to respond on the basis of how the child was in the previous 2 months. The respondent is asked to rate 99 problem items as 0 for not true of the child, 1 for somewhat or sometimes true and 2 for very true or often 
true. In addition, item 100 requests respondents to write in any additional problems that were not previously listed. Filling the CBCL 11/2- 5 forms required about 15 - 20 minutes. To determine which problem items tend to occur for a syndrome, analysis of CBCL $1 \frac{1}{2}-5$ scoring was done. The total score for each syndrome scale is computed by summing the scores of 1 and 2 for all the items of the scale. By obtaining the total score for each syndrome scale and circling the score in the column of numbers in the graphic display, one can see how the child compares with the normative sample on each scale. Higher scores indicate more of that particular behaviour problem. The total problem score includes the total of the internalising problem score, externalising score, sleep problems score and few other problems listed as "other problems." $[15]$ The content validity of CBCL $1 \frac{1}{2}-5$ scales is $\mathrm{P}<$ .01 , that is they discriminate between the referred and nonreferred children. The test-retest reliability of problem scale score was supported by a mean test-retest $r=.85$ for CBCL scores. CBCL is adopted by the investigator (Achebbach TM and Rescorla LA 2000).

The score of the internalising scale, externalising scale and total raw scores of the case were compared with the control and statistically analysed. For the purpose of analyses, the following statistical techniques were used-

1. Measures of central tendency.

2. Mann-Whitney $U$ test to find out if there is any significant difference in behaviour in children with unintentional poisoning and control group.

\section{Inclusion Criteria}

1. Children age ranging from 1.5 - 5 years.

2. Children under the care of mother and father.

3. Children as inpatient of the hospital.

4. Children with unintentional mild poisoning.

5. Children with parents who can respond to CBCL.

6. Children undergone unintentional poisoning for the first time.

7. Children came to medical college directly within three hours after the incident.

\section{Exclusion Criteria}

1. Children who drop out of the continuous IP treatment.

2. Children referred to medical college after long medication.

3. Children with parents could not respond to CBCL.

4. Children with severe poisoning.

5. Children with previous medication for behaviour problem.

\section{RESULTS}

To determine which problem items tend to occur together for a syndrome, statistical analysis of CBCL $1 \frac{1}{2}-5$ scoring was done.

1. Distribution of children without poisoning and with unintentional poisoning.

The total score of the CBCL were analysed for median and interquartile range and tabulated as shown below.

\begin{tabular}{|c|c|c|}
\hline Category & Median & IQR \\
\hline Children with poisoning & 58 & 8 \\
\hline Children without poisoning & 48 & 13 \\
\hline \multicolumn{2}{|c|}{ Table 1. Median and Interquartile Range of CBCL of } \\
Children with/without Poisoning \\
\hline
\end{tabular}

The median and the interquartile range of the total raw score of CBCL score of children with unintentional poisoning were 50 and 8 and that of non-poisoning group were 48 and 13 respectively. The median of the CBCL total raw score of children with unintentional poisoning was high compared to that of children without poison. The 25th, 50th and 75th percentile of total raw score of CBCL score of children with poisoning were 51,58 and 59 respectively. The corresponding scores of non-poisoned children were 43,48 and 56 respectively. It is inferred that the poisoned children were having more behaviour problem than children without poison.

2. Behaviour problems of children with unintentional poisoning.

a. Behaviour problems based on different aspects of CBCL. The median and interquartile range of CBCL of children with poisoning were calculated and tabulated as shown below.

\begin{tabular}{|c|c|c|c|c|}
\hline Aspects & Median & IQR & Min & Max \\
\hline Emotionally Reactive & 2 & 3 & 1.00 & 8.00 \\
\hline Anxious/ Depressed & 3 & 7 & 1.00 & 8.00 \\
\hline Somatic Complaints & 4 & 5 & 0.00 & 11.00 \\
\hline Withdrawn & 2 & 1 & 0.00 & 4.00 \\
\hline Sleep Problems & 4 & 4 & 1.00 & 12.00 \\
\hline Attention Problems & 5 & 3 & 0.00 & 9.00 \\
\hline Aggressive Behaviour & 13 & 12 & 2.00 & 23.00 \\
\hline Internalising Problems & 12 & 4 & 4.00 & 23.00 \\
\hline Externalising Problems & 18 & 15 & 2.00 & 28.00 \\
Total Problems & $\mathbf{4 5}$ & $\mathbf{1 9}$ & $\mathbf{2 3}$ & $\mathbf{8 0}$ \\
\hline Table 2. Means and Interquartile Range on CBCL \\
Scores for Children with Poisoning \\
\hline
\end{tabular}

The table shows that the median value is more than $50 \%$ closer to the maximum scores in the aspects like withdrawn (2), attention problems (5), aggressive behaviour (13), internalising (12) and externalising problems (18) and total problem scores (45) compared to that of other aspects. It is inferred that the level of behaviour problems was high in the aspects like withdrawn tendency, attention problems, aggressive behaviour, internalising and externalising problems and total problem score for unintentional poisoned children.

b. Comparison of behaviour problem of children with unintentional poisoning based on the aspect withdrawn tendency.

The Mann-Whitney U test was calculated for the scores of CBCL in withdrawn tendency aspect of children with unintentional poisoning and without poisoning.

\begin{tabular}{|c|c|c|c|c|c|}
\hline Aspect & Category & $\mathbf{N}$ & $\begin{array}{l}\text { Mean } \\
\text { Rank }\end{array}$ & $\begin{array}{l}\text { Sum of } \\
\text { Ranks }\end{array}$ & $\begin{array}{c}\text { Mann- } \\
\text { Whitney } \\
\text { U }\end{array}$ \\
\hline \multirow{3}{*}{ Withdrawn } & $\begin{array}{c}\text { With } \\
\text { poisoning }\end{array}$ & 23 & 29.2 & 671.5 & \multirow{3}{*}{$133.5^{*}$} \\
\hline & $\begin{array}{l}\text { Without } \\
\text { poisoning }\end{array}$ & 23 & 23 & 409.5 & \\
\hline & Total & 46 & & & \\
\hline
\end{tabular}


*- significant at 0.05 level.

The obtained Mann-Whitney $U$ value on withdrawn aspect is 133.5 .00 , which is significant at 0.05 level. The mean rank was 29.2 for children with poisoning and 23 for the nonpoisoned group. It shows that the children with poisoning are more withdrawn than the children without poisoning.

c. Comparison of Behaviour problem of children with unintentional poisoning based on the aspect of somatic complaints.

The Mann-Whitney U test was calculated for the scores of CBCL in somatic complaints tendency aspect of children with unintentional poisoning and without poisoning.

\begin{tabular}{|c|c|c|c|c|c|}
\hline Aspect & Category & $\mathbf{N}$ & $\begin{array}{l}\text { Mean } \\
\text { Rank }\end{array}$ & $\begin{array}{c}\text { Sum } \\
\text { of } \\
\text { Ranks }\end{array}$ & $\begin{array}{c}\text { Mann- } \\
\text { Whitney U }\end{array}$ \\
\hline \multirow{3}{*}{$\begin{array}{c}\text { Somatic } \\
\text { Complaints }\end{array}$} & $\begin{array}{c}\text { With } \\
\text { poisoning }\end{array}$ & 23 & 28.28 & 650.5 & \multirow[b]{2}{*}{$154.5^{*}$} \\
\hline & $\begin{array}{c}\text { Without } \\
\text { poisoning }\end{array}$ & 23 & 18.72 & 430.5 & \\
\hline & Total & 46 & & & \\
\hline
\end{tabular}

*- significant at 0.05 level.

The obtained Mann-Whitney $U$ value on somatic complaint aspect is 154.5 , which is significant at 0.05 level. The mean rank was 28.28 for the poisoned group and 18.72 for the non-poisoned group. It shows that the children with poisoning are having more somatic complaints than the children without poisoning.

d. Comparison of Behaviour problem of children with unintentional poisoning based on the aspect of attention problems.

The Mann-Whitney U test was calculated for the scores of CBCL in attention problems aspect of children with unintentional poisoning and without poisoning.

\begin{tabular}{|c|c|c|c|c|c|}
\hline Aspect & Category & $\mathbf{N}$ & $\begin{array}{l}\text { Mean } \\
\text { Rank }\end{array}$ & $\begin{array}{c}\text { Sum of } \\
\text { Ranks }\end{array}$ & $\begin{array}{c}\text { Mann- } \\
\text { Whitney U }\end{array}$ \\
\hline \multirow{3}{*}{$\begin{array}{l}\text { Attention } \\
\text { Problems }\end{array}$} & With poison & 23 & 31.43 & 723.00 & \multirow[b]{2}{*}{$82^{*}$} \\
\hline & $\begin{array}{l}\text { Without } \\
\text { poison }\end{array}$ & 23 & 15.57 & 358.00 & \\
\hline & Total & 46 & & & \\
\hline
\end{tabular}

- significant at 0.05 level.

The obtained value of Mann-Whitney U (82) is significant at 0.05 level. The mean ranks were 31.43 in the poisoned group and 15.57 in non-poisoned group.

It is inferred that the attention problem behaviour is more in children with unintentional poisoning than that of the children without poisoning.

e. Comparison of Behaviour problem of children with unintentional poisoning based on the aspect of aggressiveness.
The Mann-Whitney U test was calculated for the scores of CBCL in aggressive tendency aspect of children with unintentional poisoning and without poisoning.

\begin{tabular}{|c|c|c|c|c|c|}
\hline \multirow{2}{*}{ Aspect } & Group & N & $\begin{array}{c}\text { Mean } \\
\text { Rank }\end{array}$ & $\begin{array}{c}\text { Sum of } \\
\text { Ranks }\end{array}$ & $\begin{array}{c}\text { Mann- } \\
\text { Whitney } \\
\text { U }\end{array}$ \\
\hline \multirow{2}{*}{ Aggression } & With poison & 23 & 29.00 & 667.00 & \multirow{2}{*}{$138^{*}$} \\
\cline { 2 - 5 } & $\begin{array}{c}\text { Without } \\
\text { poison }\end{array}$ & 23 & 18.00 & 414.00 & \\
\cline { 2 - 5 } & Total & $\mathbf{4 6}$ & & & \\
\hline
\end{tabular}

Table 5. Result of Significance of Aggressive Aspect among Children with/without Poisoning

*-significant at 0.05 level

The obtained value of Mann-Whitney $U$ (138) is significant at 0.05 level. The mean ranks were 29 in the poisoned group and 18 in the non-poisoned group.

It is inferred that the aggressive problem is more in the children with unintentional poisoning than that of children without poisoning.

f. Comparison of Behaviour problem of children with unintentional poisoning based on the aspect of sleep problems.

The Mann-Whitney U test was calculated for the scores of CBCL in sleep problems of children with unintentional poisoning and without poisoning.

\begin{tabular}{|c|c|c|c|c|c|}
\hline Aspect & Group & N & $\begin{array}{c}\text { Mean } \\
\text { Rank }\end{array}$ & $\begin{array}{c}\text { Sum of } \\
\text { Ranks }\end{array}$ & $\begin{array}{c}\text { Mann- } \\
\text { Whitney U }\end{array}$ \\
\hline $\begin{array}{c}\text { Sleep } \\
\text { Problems }\end{array}$ & \begin{tabular}{c} 
With poison \\
\cline { 2 - 5 }
\end{tabular} & 23 & 29.39 & 676.00 & \multirow{2}{*}{$129^{*}$} \\
\cline { 2 - 5 } & poison & 23 & 17.61 & 405.00 & \\
\hline
\end{tabular}

Table 5. Result of Significance of Sleep Problems among Children with/without Poisoning

*-significant at 0.05 level.

The obtained value of Mann-Whitney U (129) is significant at 0.05 level. The mean ranks were 29.39 in the poisoned group and 17.61 in the non-poisoned group.

It is inferred that the sleep problem is more in children with unintentional poisoning than that of children without poisoning.

g. Comparison of Behaviour problem of children with unintentional poisoning based on internalising problems.

The Mann-Whitney U test was calculated for the scores of CBCL in internalising problem aspect of children with unintentional poisoning and without poisoning.

\begin{tabular}{|c|c|c|c|c|c|}
\hline Aspect & Category & $\mathbf{N}$ & $\begin{array}{l}\text { Mean } \\
\text { Rank }\end{array}$ & $\begin{array}{c}\text { Sum } \\
\text { of } \\
\text { Ranks }\end{array}$ & $\begin{array}{c}\text { Mann- } \\
\text { Whitney } \\
\text { U }\end{array}$ \\
\hline \multirow{3}{*}{$\begin{array}{c}\text { Internalising } \\
\text { Problems }\end{array}$} & With poison & 23 & 30.43 & 700.00 & \multirow[b]{2}{*}{$105^{*}$} \\
\hline & $\begin{array}{l}\text { Without } \\
\text { poison }\end{array}$ & 23 & 16.57 & 381.00 & \\
\hline & Total & 46 & & & \\
\hline \multicolumn{6}{|c|}{$\begin{array}{l}\text { Table 6. Result of Significance of Internalising Problem } \\
\text { Aspect among Children with/without Poisoning }\end{array}$} \\
\hline
\end{tabular}

*-significant at 0.05 level. 
The obtained value of Mann-Whitney $U$ test (105.0) is significant at 0.05 level. The mean ranks were 30.43 for poisoned group and 16.57 in the non-poisoned group. This shows that the children with poisoning have high internalising problems than that of children without poisoning.

h. Percentage distribution of children with unintentional poisoning based on level/ degree of internalising problem.

\begin{tabular}{|l|c|c|c|c|}
\hline Category & Aspect & Degrees of IP & Frequency & \% \\
\hline \multirow{4}{*}{ Poisoned } & & Clinical & - & 00 \\
\cline { 3 - 5 } & Internalising & Borderline & 4 & 17 \\
\cline { 3 - 5 } & Problems (IP) & Normal & 19 & 83 \\
\cline { 3 - 5 } & & Total & $\mathbf{2 3}$ & $\mathbf{1 0 0 . 0}$ \\
\hline
\end{tabular}

Table 7. Percentage Distribution of Internalising Problems of Children with Unintentional Poisoning

Out of 23 cases studied, 4 children were in the borderline clinical range with respect to the internalising problems, that is $17 \%$ were in the borderline clinical range.

i. Comparison of Behaviour problem of children with unintentional poisoning based on the aspect of externalising problem.

The Mann-Whitney U test was calculated for the scores of CBCL in externalising problem aspect of children with unintentional poisoning and without poisoning.

\begin{tabular}{|c|c|c|c|c|c|}
\hline Aspect & Category & N & $\begin{array}{c}\text { Mean } \\
\text { Rank }\end{array}$ & $\begin{array}{c}\text { Sum } \\
\text { of Ranks }\end{array}$ & $\begin{array}{c}\text { Mann- } \\
\text { Whitney } \\
\text { U }\end{array}$ \\
\hline \multirow{4}{*}{$\begin{array}{c}\text { Externalising } \\
\text { Problems }\end{array}$} & $\begin{array}{c}\text { With poison } \\
\text { Without } \\
\text { poison }\end{array}$ & 23 & 30.11 & 692.5 & \multirow{2}{*}{$112.5^{*}$} \\
\cline { 2 - 5 } & Total & $\mathbf{4 6}$ & & & \\
\hline
\end{tabular}

Table 8. Result of Significance of Externalising Problem Aspect among Children with/without Poisoning

- Significant at 0.05 level.

The obtained Mann-Whitney $U$ value in externalising problems (112.5.00) is significant at 0.05 level. The mean rank of poisoned and non-poisoned group was 30.11 and 16.89 respectively. This shows that children with poisoning have high externalising problems than the children without poisoning.

j. Percentage distribution of children with unintentional poisoning based on level/ degrees of externalising problem.

\begin{tabular}{|c|c|c|c|c|}
\hline Category & Aspect & $\begin{array}{c}\text { Degrees } \\
\text { of EP }\end{array}$ & Frequency & $\%$ \\
\hline \multirow{4}{*}{ Poisoned } & \multirow{4}{*}{$\begin{array}{c}\text { Externalising } \\
\text { Problems } \\
\text { (EP) }\end{array}$} & Clinical & 0 & 00 \\
\hline & & Borderline & 2 & 8 \\
\hline & & Normal & 21 & 92 \\
\hline & & Total & 23 & $\begin{array}{c}10 \\
0 . \\
0\end{array}$ \\
\hline
\end{tabular}

Table 9. Percentage Distribution of Externalising Problems of Children with Unintentional Poisoning

Out of 23 children studied, 2 were in the borderline clinical range with respect to externalising problems.

k. Comparison of Behaviour problem of children with unintentional poisoning based on the aspect of total problem.
The Mann-Whitney U test were calculated for the scores of CBCL in total problem aspect which include the total of internalising problem score, externalising score, sleep problems score and few other problems listed as "other problems" among children with unintentional poisoning and without poisoning.

\begin{tabular}{|c|c|c|c|c|c|}
\hline \multirow{2}{*}{ Aspect } & Category & N & $\begin{array}{c}\text { Mean } \\
\text { Rank }\end{array}$ & $\begin{array}{c}\text { Sum of } \\
\text { Ranks }\end{array}$ & $\begin{array}{c}\text { Mann- } \\
\text { Whitney } \\
\text { U }\end{array}$ \\
\hline \multirow{2}{*}{$\begin{array}{c}\text { Total } \\
\text { Problems }\end{array}$} & With poison & 23 & 31.04 & 692.5 & $91.00^{*}$ \\
\cline { 2 - 6 } & Without poison & 23 & 15.96 & 388.5 & \\
\cline { 2 - 5 } & Total & $\mathbf{4 6}$ & & & \\
\hline $\begin{array}{c}\text { Table 10. Result of Significance of Total Problem Aspect } \\
\text { among Children with/ without Poisoning }\end{array}$ \\
\hline
\end{tabular}

*- significant at 0.05 level.

The obtained Mann-Whitney U value (91.00) is significant at 0.05 level. The mean rank of children with poison and without poison were 31.04 and 15.96 respectively. It shows that children with poisoning have high total problems than that of the children without poisoning.

l. Percentage distribution of children with unintentional poisoning based on level/ degrees of total problem.

\begin{tabular}{|l|c|c|c|c|}
\hline Category & Aspect & Degrees of TP & Frequency & $\mathbf{\%}$ \\
\hline \multirow{4}{*}{ Poisoned } & & Clinical & 3 & 13.04 \\
\cline { 3 - 5 } & Total & Borderline & 1 & 4.3 \\
\cline { 3 - 5 } & & Normal & 19 & 82.6 \\
\cline { 3 - 5 } & & Total & $\mathbf{2 3}$ & $\mathbf{1 0 0 . 0}$ \\
\hline
\end{tabular}

Table 11. Percentage Distribution of Total Problems of Children with Unintentional Poisoning

Of the 23 cases that were studied, 1 child had borderline clinical range on total problems and 3 children were in the clinical range; that is $4.3 \%$ were in the borderline clinical range and $13.04 \%$ were in the clinical range.

\section{DISCUSSION}

1. The mean and median of the CBCL total score of children with unintentional poisoning was high as that of children without poison. It is found that the children who consumed poison were having more behaviour problem than children without poison.

2. The level of behaviour problems in children were high in the aspects like withdrawn tendency, somatic complaints, attention problems, aggressive behaviour, sleep problems, internalising and externalising problems among unintentional poisoning.

3. There is a significant difference in the withdrawn behaviour and somatic complaints between the children with unintentional poisoning and children without poisoning. It is found that the children with poisoning are more withdrawn and had somatic complaints than the children without poisoning.

4. There exists a significant difference in the attention problem between the children with unintentional poisoning and children without poisoning. The attention problem behaviour is more in children with unintentional poisoning than that of children without poisoning. 
5. There exists a significant difference in the aggressive problem between the children with unintentional poisoning and children without poisoning. The aggressive behaviour is more in the children with unintentional poisoning than that of children without poisoning.

6. There exists a significant difference in sleep problems between the children with unintentional poisoning and children without poisoning.

7. Significant difference in the internalising problem was seen between the children with unintentional poisoning and children without poisoning. Internalising problems were seen more in children with poisoning.

8. There exists a significant difference in the externalising problem between the children with unintentional poisoning and children without poisoning. It is found that children with poisoning have high externalising problems than the children without poisoning.

9. There exists a significant difference in the total problems between the children with unintentional poisoning and children without poisoning.

It is found that children with poisoning have high total problems than that of children without poisoning. In this study, out of 23 children who came with poisoning, 19 had scores in the normal range and 4 had scores in the borderline range for internalising problems. In the externalising problem scores, out of 23 cases studied 21 had normal score and 2 had borderline score. When the total problem score was studied, it was seen that out of 23 cases 1 child had borderline score and 3 were in the clinical range. These kids can be referred to mental health professionals for help.

\section{CONCLUSION}

The behavioural characteristics in children who were admitted with unintentional poisoning between the age group of $11 / 2-5$ years were compared to the age and sex matched children who were admitted with minor illness who were taken as controls. CBCL $1 \frac{1}{2}-5$ years was used to assess the behavioural problems. Children with unintentional poisoning were found to have significant externalising problems like aggressiveness and attention problems. These children were also having internalising problems like withdrawn symptoms and somatic complaints compared to the controls. In addition to the externalising and internalising problems, they were having more sleep problems also. So the parents can be made aware of the behaviours of the child, which can lead to unintentional poisoning and precautionary measures can be taken.

\section{Contributions}

JMA collected the data, conducted the study and prepared the manuscript and will be the guarantor of the paper. PTB guided the study, gave statistical support and reviewed the manuscript. BKP, SSV and DSM supported the study and critically reviewed the manuscript.

\section{REFERENCES}

[1] Hyder AA, Sugerman DE, Puvanachandra P, et al. Global childhood unintentional injury surveillance in four cities in developing countries: a pilot study. Bull World Health Organ 2009;87(5):345-52.

[2] Pedan M, Oyegbite K, Ozanne-smith J, et al. World report on child injury prevention. Geneva: World Health Organisation \& United Nations Children's Fund, 2008.

[3] Dutta AK, Seth A, Goyal PK, et al. Poisoning in children: Indian scenario. Indian J Pediatrics 1998;65(3):36570.

[4] Sibert JR, Newcombe RG. Accidental ingestions of poisons and child personality. Post Graduate Medical Journal 1977;53(619):254-6.

[5] Margolis R. Psychological study of childhood poisoning: a 5-year follow up. Am Acad Pediatrics 1971;47(2).

[6] Acar E, Dursun OB, Esin IS, et al. Unintentional injuries in preschool age children. Is there a correlation with parenting style and parental attention deficit and hyperactivity symptoms. Medicine (Baltimore) 2015;94(32):e1378.

[7] Lange H, Buse J, Bender S, et al. Accident proneness in children and adolescents affected by ADHD and the impact of medication. J Atten Disord 2014;27:1-9.

[8] American Psychiatric Association. Cautionary statement for forensic use of DSM-5. Diagnostic and statistical manual of mental disorders. $5^{\text {th }}$ edn. 2013.

[9] Bayer KJ, Ukoumunne OC, Mathers M, et al. Development of children's internalizing and externalizing problems from infancy to five years of age. Australian and New Zealand of Psychiatry 2012;46(7):659-68.

[10] Jokela M, Power C, Kiwimaki M. Childhood problem behaviours and injury risk over the life course. J child Psychol Psychiatry 2009;50(12):1541-9.

[11] Basavaraj DS, Forster DP. Accidental poisoning in young children. Journal of Epidemiology and community Health 1982;36(1):31-4.

[12] de la Osa N, Granero R, Trepat E, et al. The discriminative capacity of CBCL/1 1/2-5 DSM5 scales to identify disruptive and internalizing disorders in preschool children. Eur Child Adolesc Psychiatry 2016;25(1):17-23.

[13] Glania $\mathrm{T}$, Lialiaris $\mathrm{T}$, Tripsianis $\mathrm{G}$, et al. Is psychopathology related to children's unintentional injury? Int J Adolesc Med Health 2010;22(4):567-73.

[14] Schwebel DC, Roth DL, Elliott MN, et al. Association of externalizing behavior disorder symptoms and injury among fifth graders. Acad Pediatr 2011;11(5):427-31.

[15] Achenbach TM, Rescorla LA. Manual for the ASEBA preschool forms \& profiles. University of Vermont, Research Center for Children, Youth \& Families. Burlington, VT: 2000. 